Int. J. Dev. Biol. 59: 221-228 (2015)

doi: $10.1387 / \mathrm{ijdb} .140195 \mathrm{LB}$

\title{
Analysis of AtGUS1 and AtGUS2 in Arabidopsis root apex by a highly sensitive TSA-MISH method
}

\author{
LEONARDO BRUNO*,1, MATTEO RONCHINI ${ }^{2}$, OLIMPIA GAGLIARDI ${ }^{1}$, TAMARA CORINTI², \\ ADRIANA CHIAPPETTA ${ }^{1}$, PAOLO GEROLA ${ }^{2}$ and MARIA B. BITONTI ${ }^{1}$ \\ ${ }^{1}$ Department of Biology, Ecology and Earth Science, University of Calabria, Laboratory of Plant Biology, Cosenza and \\ ${ }^{2}$ Department of Teorethical and Applied Sciences, University of Insubria, Varese, Italy
}

\begin{abstract}
A new highly sensitive whole-mount in situ hybridization method, based on tyramide signal amplification (TSA-MISH) was developed and a combined GFP detection andTSA-MISH procedure was applied for the first time in plants, to precisely define the spatial pattern of AtGUS1 and AtGUS2 expression in the root apex. $\beta$-glucuronidases (GUSs) belonging to the glycosyl hydrolases (GHs) 79 family, are widely distributed in plants, but their functional role has not yet been fully investigated. In the model system Arabidopsis Thaliana, three different AtGUS genes have been identified which encode proteins with putative different fates. Endogenous GUS expression has been detected in different organs and tissues, but the cyto-histological domains of gene expression remain unclear. The results here reported show co-expression of AtGUS1 and AtGUS2 in different functional zones of the root apex (the cap central zone, the root cap meristem, the staminal cell niche and the cortical cell layers of the proximal meristem), while AtGUS2 is exclusively expressed in the cap peripheral layer and in the epidermis in the elongation zone. Interestingly, both genes are not expressed in the stelar portion of the proximal meristem. A spatial (cortex vs. stele) and temporal (proximal meristem vs. transition zone) regulation of AtGUS1 and AtGUS2 expression is therefore active in the root apex. This expression pattern, although globally consistent with the involvement of GUS activity in both cell proliferation and elongation, clearly indicates that AtGUS1 and AtGUS2 could control distinct downstream process depending on the developmental context and the interaction with other players of root growth control. In the future, the newly developed approaches may well be very useful to dissect such interactions.
\end{abstract}

KEY WORDS: Arabidopsis thaliana, multiprobe in situ hybridization, GUS, root, tyramide signal amplification (TSA)

$\beta$-glucuronidases (GUS) are glycosyl hydrolases (GHs) which catalyse the hydrolysis of the glycosidic bond between glucuronic acid and other carbohydrates or molecules different from sugars, termed aglycones. GUSs have been identified in all the living organisms and according to their amino acid sequence, have been classified in three families: GH1 GH2 e GH79 (Henrissat, 1991; Henrissat and Bairoch, 1993; Henrissat and Bairoch, 1996).

GUS, belonging to GH79 family, are widely distributed in plants. GUS sequence was determined for the first time in Scutellaria baicalensis (Sasaki et al., 2000) and three different GUS genes have been identified in Arabidopsis Thaliana and named AtGUS1, AtGUS2 and AtGUS3 (Fig. 1) (Woo et al., 2007). Further analysis of plants genomes and transcriptomes confirmed the wide distribution of GH79 GUSs in plants (Honys and Twell, 2004; Pina et al., 2005; Arul et al., 2008; Konishi et al., 2008; Matas et al., 2011;
Hafidh et al., 2012). PCR and endogenous GUS activity analysis demonstrated their expression in all the different organs (Sood, 1980; Schulz and Weissenböck, 1987; Plegt and Bino, 1989; Hu et al., 1990; Alwen et al., 1992; Anhalt and Weissenböck, 1992; Wozniak and Owens, 1994; Morimoto et al., 1995; Morimoto et al., 1998; Muhitch, 1998; Sudan et al., 2006; Schoenbeck et al., 2007; Woo et al., 2007).

The different roles proposed for GUSs in plants can be associated with changes in polysaccharide moieties (Sudan et al., 2006; Eudes et al., 2008) or to the release of signal molecules (Schulz and Weissenböck, 1987; Morimoto et al., 1998; Wen et al., 2004;

Abbreviations used in thispaper: GH, glycosyl hydrolase; GUS, $\beta$-glucuronidases; MISH, multiprobe in situ hybridization; TSA, tyramide signal amplification.

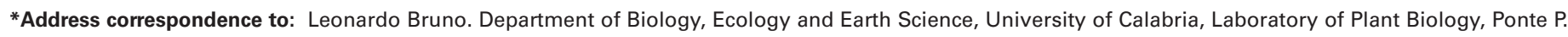
Bucci, Cubo 6B, 87036, Arcavacata di Rende, Cosenza Italy. E-mail: leonardo.bruno@ unical.it -Tel:+39-0984-492964
}

Accepted: 25 March 2015

ISSN: Online 1696-3547, Print 0214-6282 
Woo et al., 2005; Hirunuma et al., 2011). GUS in plants has been demonstrated to be involved in modulating the glycosylation degree of arabinogalactanproteins (Eudes et al., 2008) and in the changes in cell wall composition associated to cell elongation (Sudan et al., 2006; Eudes et al., 2008). Glucuronic acid and 4-O-methyl glucuronic acid residues are present in xylans, rhamnogalacturonans II and arabinogalactan proteins (Ishii and Matsunaga, 1996; Renard et al., 1999; Zhong et al., 2005; Koutaniemi et al., 2012; Urbanowicz et al., 2012); their removal by GUS is required for further hydrolysis of the polysaccharide moiety by other glycosyl hydrolases (Eudes et al., 2008).

Concerning the role of GUS in modulating the presence of signal molecules, it works in opposition/coordination to $\beta$-glucuronosyltransferase (UGTs) enzymes, responsible of glucuronic acid addition to different molecules with their consequent physiological inactivation: one enzyme reverses the action of the other. This has been demonstrated in $S$. baicalensis, where the presence of baicalein has been found to be under the coordinate control of UGT and GUS activities (Morimoto et al., 1998; Hirunuma et al., 2011).

Interestingly, this UGT and GUS combined opposite function seems to operate in the regulation of cell division in the root cap meristem. It has been demonstrated that, in Pisum sativum, UGT (PsUGT1) plays a key role in cell cycle regulation by glycosylating, and therefore removing, a mitosis inhibitor, probably a flavonoid, which is instead released by GUS, with consequent cell cycle inhibition (Wen et al., 2004; Woo et al., 2005). This is supported by the observation that in several species (pea, alfalfa and A.thaliana) uidA expression under the PsUGT1 promoter was lethal (Wen et al., 2004). Moreover, inhibition of GUS activity through saccharolactone causes an enhanced production of border-like cells in the root apex of $A$. thaliana, indicating an increase in the mitotic activity of root cap meristem (Wen et al., 2004).

Currently, despite the relevance of a time and space-dependent modulation of gene expression in the developmental processes, data on the cyto-histological domains of endogenous GUS expression in plants are inadequate, being mainly based on semiquantitative PCR analysis or GUS detection (Woo et al., 2007). In particular, semiquantitative PCR analysis performed on whole organs showed that all the three AtGUS genes are expressed in the roots of Arabidopsis Thaliana although AtGUS3 was expressed at a lower extent. AtGUS expression was also analysed in pro AtGUS:: uidA transgenic lines of Arabidopsis Thaliana. Histochemical detection revealed a similar expression pattern of AtGUS1, AtGUS2 and AtGUS3 in the root apex, but precise tissue localization is lacking.

To add information on these aspects we applied the whole mounting multiprobe in situ hybridization technique (MISH) set up in our laboratory (Bruno et al., 2011), which represents a powerful techniques allowing the simultaneous localization at cellular level of different gene transcripts (Bruno et al., 2011). Therefore, based on the predicted different fate of AtGUSs proteins (Woo et al., 2007), we planned to investigate the expression pattern of AtGUS1 (coding for secretory protein) vs AtGUS2 (coding for membrane associated protein) in root apex.

Through this approach we observed that AtGUS1 and AtGUS2

Fig. 1. Alignment of AtGUS1 (AT5G61250), AtGUS2 (AT5G07830) and AtGUS3 (AT5G34940) nucleotide sequences from The Arabidopsis Information Resource (TAIR). Yellow and green colours mark the region selected for synthesizing AtGUS1 and ATGUS2 riboprobes, respectively.

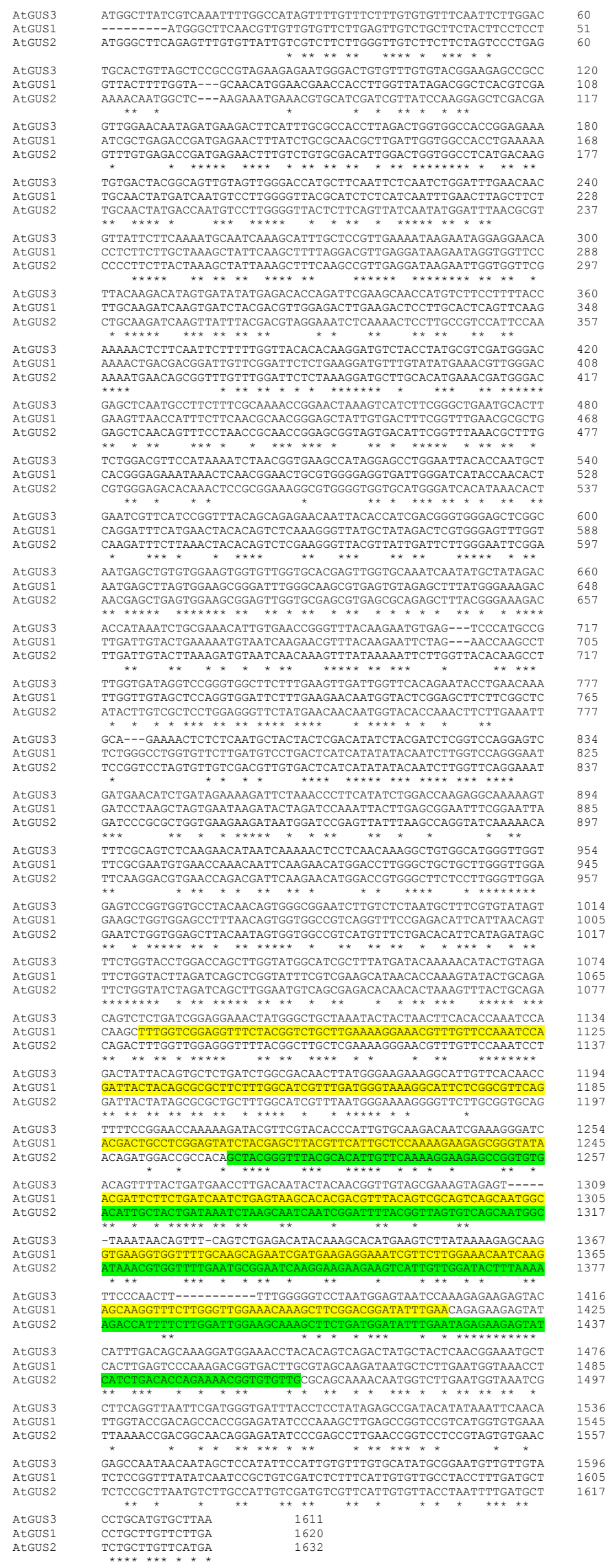


transcripts largely co-localize but none of the transcripts could be detected in the stelar region of the proximal meristem, indicating that both genes are not expressed in that region. However, it could be not excluded that, in the applied hybridization conditions, gene expression in the proximal meristem stele could not be detectable since very low as compared to that of the other root zones. Therefore the aim of the present work was to develop an upgraded MISH method which, through the application of Tyramide Signal Amplification (TSA) approach (Molecular probes), enables to detect also very low levels of gene expression.

The new TSA-MISH method was first verified by localizing in both the root and shoot apex of $A$. thaliana seedlings the transcripts of ELONGATA 3 gene (ELO3), whose spatial expression in dividing tissue is known. Thereafter it was used for the localization of AtGUS1 and AtGUS2 transcripts in the root apex. In addition a combined GFP labelling - mRNA hybridization approach was applied to transgenic lines of $A$. thaliana expressing GFP-linked SCARECOW (SCR) protein under its promoter (pro SCR:GFP:SCR) useful for a precise identification of cortex-stele boundaries.

Altogether these approaches allowed to clearly define the expression pattern of AtGUS1 and AtGUS2 in the root apex, thus providing additional informations useful for the definition of their putative functional role.

\section{Results and Discussion}

\section{TSA-MISH versus MISH}

The main difference of TSA-MISH versus MISH (Bruno et al., 2011) deals with the detection phase. In both techniques appropriate different RNA-probes are constructed by using nucleotides modified with components specific for each probe. In the MISH, fluorescent antibodies are used to detect the specific probes. Therefore, signal intensity depends on the length of the probe, the percentage of modified nucleotides used in probe construction and the fluorescence efficiency of the compound used in probe detection. Instead, in TSA-MISH, peroxidase conjugated antibodies specifically react with the different modified nucleotides and a particular "fluorescent" reaction is used for their detection. Tyramide associated to a fluorofor (F-TYR) is the reaction substrate: the F-TYR oxidized product is a highly reactive radical which binds to nucleophilic residues, thus avoiding diffusion away from the detected probe (Fig. 2). Longer the incubation time, stronger the fluorescent signal associated to the probe. More probes, differently labelled, can be analysed together, by repeating the following steps: $\mathrm{H}_{2} \mathrm{O}_{2}$ treatment to inactivate the peroxidases - treatment with the anti-antibody specific for the probe - FTSA peroxidase reaction (see method's work flow in Fig. 3).

Note that in the work flow (Fig. 3) it has been also highlighted that, when available, antibody versus the encoded protein can be added together with the antibody vs the relative mRNA-probe. Therefore a possible and very relevant extension of this technique is the concomitant detection of transcription (mRNA) and translation (proteins) products, useful to analyse the whole regulation of gene expression.

\section{Validation of the TSA-MISH}

The reliability of the method was tested by investigating the expression pattern of the ELO3 gene in the shoot as well as in the root apex of young $A$. thaliana seedlings.

ELO3 is a component of a conserved histone acetyl transferase complex, that co-localizes with the elongating RNAPOLYMERASE II (RNAP II) and targets genes for histone H3 acetylation (Nelissen et al., 2010). Previously, tissue-specific expression pattern of ELO3 was investigated through ISH and MISH techniques in both $A$. thaliana seedlings as well as during embryo development (Nelissen et al., 2010; Bruno et al., 2011; Himanen et al., 2012) According to the role of ELONGATOR complex in cell proliferation, ELO3expression in seedling was confined to meristematic regions and proliferating cells.

The results obtained by using TSA-ISH (Fig. 4) fully matches that previously observed (Nelissen et al., 2010; Bruno et al., 2011). Indeed in both the present and the previous experiments (Nelissen et al., 2010; Bruno et al., 2011) ELO3 transcripts are present in the shoot meristematic dome, in the emerging leaf primordia, in the blastozone of developing organs and provascular strands (Fig. 4A). In the primary root, a strong ELO3 expression is evident in the whole proximal meristem, being detected in stem cell niche, as well as protoderm, cortex and in the vascular stele (Fig. 4B).

These results clearly show that the upgraded procedure does not affect neither the penetrability of the probe into the tissues, being detected also in the stele, nor the efficiency of probes and antibodies, thus demonstrating the reliability of TSA-based method.

\section{Expression pattern of AtGUS1 and AtGUS2 genes in root apex trough MISH vs TSA-MISH}

AtGUS1 and AtGUS2 putatively encode protein with different fate: secretory and membrane-associated respectively (Woo et

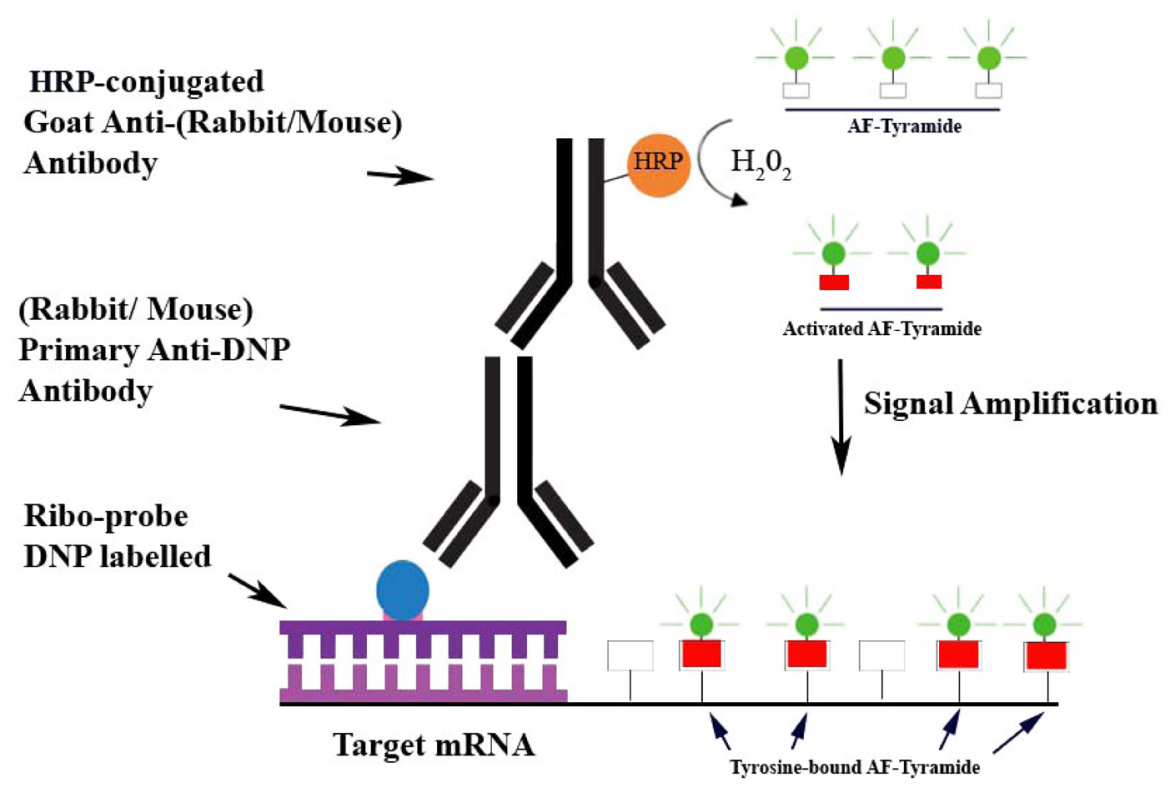

AF-Tyramide: Alexa Flour labelled Tyramide derivative

Fig. 2. Schematic representation of TSA detection applied to MISH. HRP, horseradish peroxidase; $\mathrm{H}_{2} \mathrm{O}_{2}$, hydrogen peroxide. 
al., 2007). Since patterning and organization of Arabidopsis root meristem into different functional zones are well defined processes (Dolan et al., 1993), we selected to perform our study on root apex as a suitable system for defining the relationship between spatial GUSs expression pattern and cell commitment.

The expression pattern obtained through MISH approach shows that spatial accumulation of AtGUS1 and AtGUS2 transcripts in the root apex overlaps (Fig. $5 \mathrm{~A}, \mathrm{~B}, \mathrm{C}$ ). In particular the presence of both transcripts is clearly evident in the cap central zone (columella), in the root cap meristem, in the staminal cell niche, in the epidermis and in the cortical cell layers of proximal meristem, whereas AtGUS1 and AtGUS2 expression is not detectable in the stele. Faint AtGUS2 expression is observable in the cap outermost layer (Fig. 5B).

A higher hybridization signal in a lower background is observed when TSA-MISH is applied to detect AtGUS1 and AtGUS2 expression pattern in the root apex (Fig. 5A',B',C'), thus demonstrating the high sensitivity of the new approach. Interestingly, the high sensitivity of the new detection method clearly evidenced a differential expression of the two genes: i.e. only AtGUS2 is expressed in the cap external layer (Fig. 5 B'). Moreover, in the transition zone AtGUS1 transcripts are not any more detectable along the epidermis, highlighting a temporal regulation of its expression (proximal meristem vs elongation zone) (Fig. $5 \mathrm{~A}^{\prime}$ ). Despite this higher sensitivity, the signal associated to AtGUS1 and AtGUS2 transcript is again not detectable in the stele of the proximal meristem, confirming the results obtained by MISH. (Fig. 5 B',C'). Longer incubation times during the peroxidase reaction, which enhances the fluorescent signal, do not change such expression pattern (data not shown). This result further supports the absence of AtGUS1 and AtGUS2 expression in the stele.

Finally, we decided to analyse AtGUS1 and AtGUS2 expression in proSCR:GFP:SCR (SGS) transgenic lines of $A$. thaliana. Namely, SCARECROW (SCR) is a member of the GRAS transcription factor family (Lee et al., 2008) and its expression is strictly confined to the pericycle cell line (Pysh et al., 1999). Therefore, in the root of $S G S$ plants. GFP fluorescent signal precisely marks the cortex-stele boundary allowing an accurate identification of AtGUS1 and AtGUS2 expression domains. However simultaneous GFP fluorescence detection and gene transcript localization was not possible so far (Darby et al., 2006) because the heat treatment necessary for MISH, irreversibly denatures GFPs and quenches their fluorescence (Bokman and Ward, 1981; Ward, 1981; Ward and Bokman, 1982). To overcome such problem new antibodies have been recently raised against heat denatured GFP and used in a combined GFP labelling - mRNA hybridization study on neuron of mice (Nakamura et al., 2008). We successfully applied this technique for the first time in plants, simultaneously localizing GFP and AtGUS1 and AtGUS2 transcripts in SGS roots. By highlighting pericycle cell line through GFP-signal we clearly confirmed

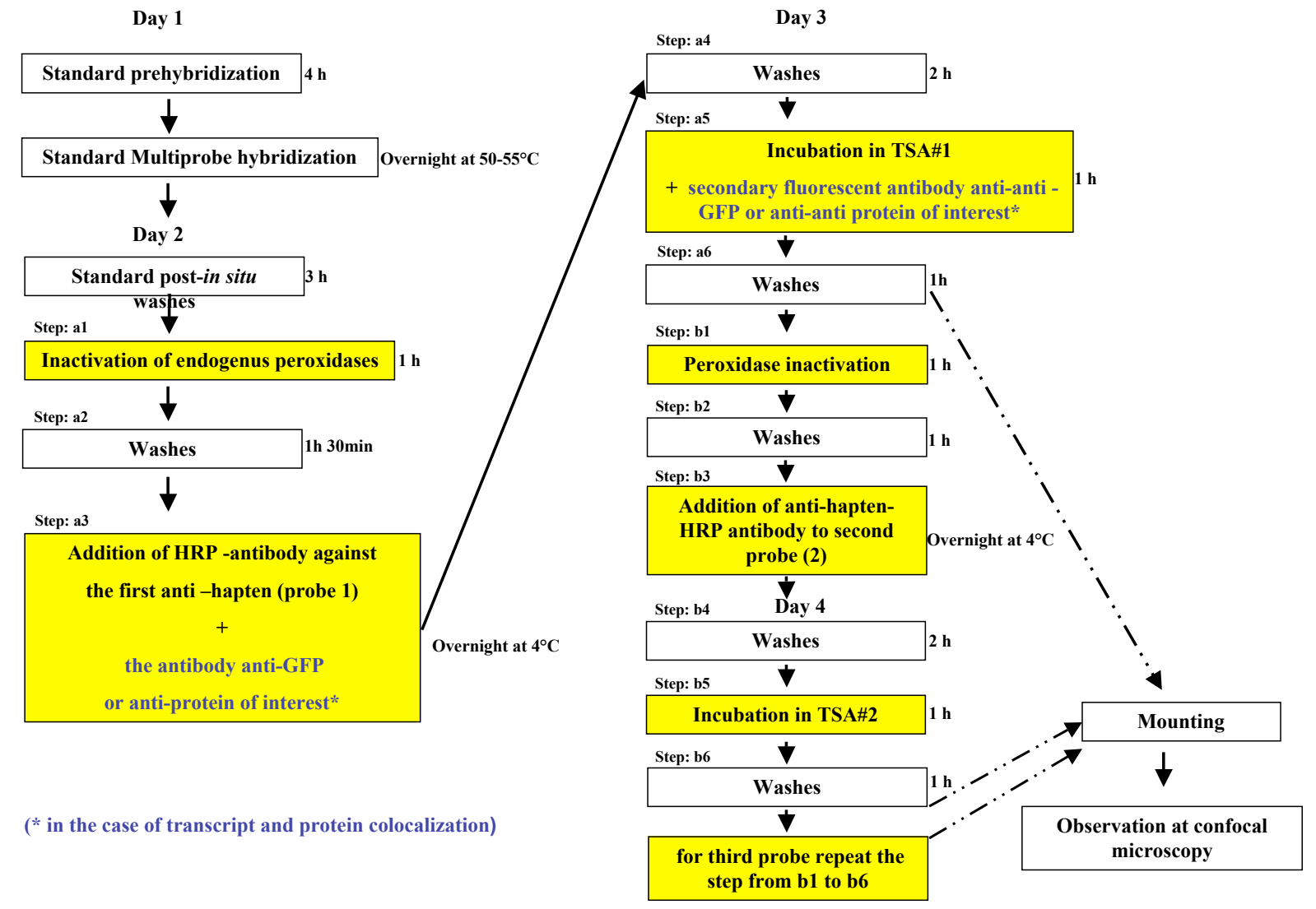

Fig. 3. Workflow of Multiprobe in situ hybridization by TSA (TSA-MISH). Yellow boxes highlight relevant points for the development of procedure with respect to MISH. Approximate times required for each step are indicated. Day 1 is primarily dedicated to steps common to standard MISH. Day 2 and 3 are dedicated to endogenous peroxidase inactivation and detection of the first anti-hapten. Subsequent couple of days are dedicated to the detection of other anti-hapten. 
that in the proximal meristem the expression of AtGUS1 (Fig. 6 $\mathrm{B}, \mathrm{C}$ ) and AtGUS2 (data not shown) is excluded from the stele, detailing a spatial (cortex versus stele) regulation of AtGUS1,2 expression.

Moreover, these results (Fig. 6 A,C) confirmed the absence of that AtGUS1 expression in the epidermis of elongation zone and evidenced that at a major distance from the cup-meristem junction AtGUS1 and AtGUS2 (data not shown) are expressed also in the stele, thus indicating that also in this region gene expression is temporally regulated (Fig. $6 \mathrm{~A}, \mathrm{C}$ ).

The presence of AtGUS1 and AtGUS2 transcripts in the stem cell niche, encompassing quiescent centre and surrounding initial cells which slowly progress into cell cycle (Clowes, 1954; Scheres, 2007), as well as their simultaneous absence in the stelar proximal meristem, appear consistent with the proposed UGT and GUS opposite effect on the regulation of cell division. Indeed, it has been demonstrated that, in Pisum sativum UGT1, binding to glucuronic acid, sequesters a mitotic inhibitor, probably a flavonoid, whose release by GUS causes cell cycle inhibition (Wen et al., 2004; Woo et al., 2007). AtGUS1 and AtGUS2 expression in the root transition zone, where cells stop dividing and start to elongate and differentiate, might be related to GUS involvement in the cell wall modifications required for cell differentiation (Sudan et al., 2006; Eudes et al., 2008).

However, the action of AtGUS1 and AtGUS2 in root patterning and growth appears to be more complex. Indeed, AtGUS1 and AtGUS2 transcripts strongly accumulate in the cortical region of the proximal meristem (Moubayidin et al., 2013) despite the
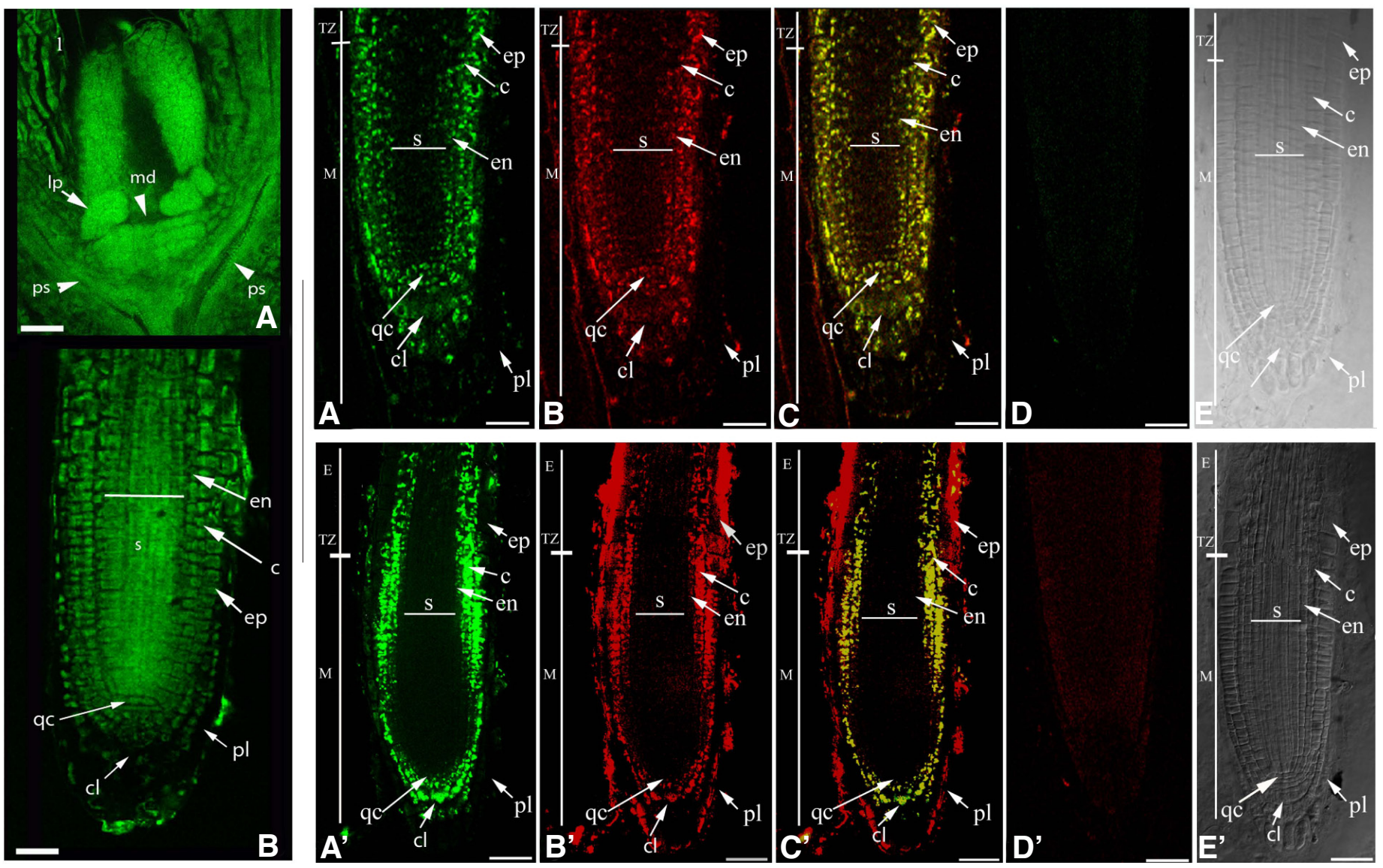

Fig. 4 (Left). ELO3 in situ hybridization by TSA-ISH (A) in the shoot and (B) in the root apical meristems. The samples have been treated with ELO3 Bio-riboprobe, mouse monoclonal anti-Bio primary antibody and HRP-goat anti-mouse IgG secondary antibody; detection by AF488-tyramide treatment. KEY: AF, Alexa Fluor dye; Bio, biotin; cl, columella; c, cortex; en, endodermis; ep, epidermis; HRP, horseradish peroxidase; Ip, leaf primordium; md, shoot meristematic dome; pl, cap peripheral layers; ps, provascular strand; qc, quiescent center; s, stele; Images by fluorescence were acquired through Leica inverted TCS SP8 confocal scanning laser microscope, with a 40X oil immersion objective. Scale bars $35 \mu \mathrm{m}$.

Fig. 5 (Right). AtGUS1 and AtGUS2 multi-probe in situ hybridization (A-D) by MISH and (A'- D') by TSA- MISH (A, A') AtGUS1 expression; (B,

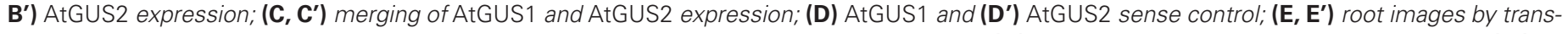
mission light. Green: samples treated with AtGUS1 Bio-riboprobe and mouse anti-Bio followed (A) by AF488-Donkey anti-mouse IgG (MISH) or (A') by HRP-goat anti-mouse IgG plus AF488 Tyramide treatment (TSA-MISH). Red: samples treated with AtGUS2 Dig-riboprobe and sheep anti-Dig, followed (B) by AF555 Donkey anti-sheep (MISH) or (B') HRP-goat anti-sheep IgG plus AF555 Tyramide treatment (TSA-MISH). KEY: AF, Alexa Fluor dye; Bio, biotin; Cl, columella; c, cortex; Dig, digoxigenin; E, elongation zone; en, endodermis; ep, epidermis; HRP, horseradish peroxidase; $M$, meristematic zone; pl, cap peripheral layers; qc, quiescent center; s, stele; TZ, transition zone; Images were acquired through Leica inverted TCS SP8 confocal scanning laser microscope, with a 40X oil immersion objective. (A-D) and ( $\left.\mathbf{A}^{\prime}-\mathbf{D}^{\prime}\right)$ image by fluorescence; (E, $\left.\mathbf{E}^{\prime}\right)$ images by transmission light. Scale bars (A-E) $50 \mu \mathrm{m} ;\left(\mathrm{A}^{\prime}-\mathrm{E}^{\prime}\right) 45 \mu \mathrm{m}$. 


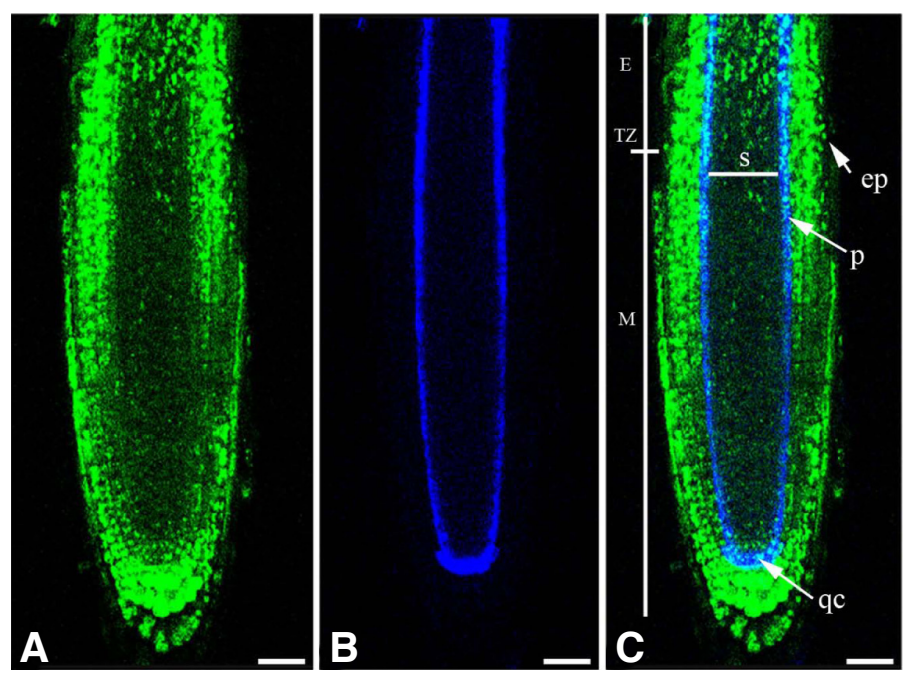

Fig. 6. AtGUS1 expression in the root apex of proSCR:GFP:SCR (SGS) Arabidopsis transgenic plants. (A) AtGUS1 Expression by TSA-MISH; (B) SCR expression by GFP detection; (C) merging of (A) and (B). Green: sample treated with AtGUS1 Bio-riboprobe and mouse anti-Bio followed by HRP-goat anti-mouse IgG plus AF488 Tyramide treatment. Blue: samples treated with rabbit anti-heat denaturated GFP plus AF647 Donkey antirabbit IgG. KEY: AF, Alexa Fluor dye; Bio, biotin; E, elongation zone; HRP, horseradish peroxidase; $M$, meristematic zone; $p$, pericycle; qc, quiescent center; s, stele; TZ, transition zone; Images by fluorescence were acquired through Leica inverted TCS SP8 confocal scanning laser microscope. Scale bars, 35 um.

presence of proliferating cells. However, as indicated also by the predicted different fate of AtGUSs proteins, GUS expression can be associated with different roles and it is largely known that complex genetic network and hormonal interactions regulate root apex establishment and maintenance through the homeostasis between cell proliferation and differentiation, thus assuring correct root growth (Blilou et al., 2005; Dello loio et al., 2007; Moubayidin et al., 2013). Further investigations are required, particularly on AtUGT85A versus AtGUS expression and on the simultaneous investigation of other compounds acting in the control of root growth, like auxins and cytokinins. Thus the method developed in the present paper, which allows the colocalization of transcripts and different antigenic molecules, will be very helpful to dissect such interactions.

\section{Conclusion}

In the present work a highly sensitive in situhybridization method (TSA-MISH) has been developed. Through this method and taking advantage of a combined TSA-MISH and GFP detection, it was possible to accurately co-localize AtGUS1 and AtGUS2 transcripts in the same root apex. TSA-MISH was useful to confirm that both genes are effectively not expressed in the stelar proximal meristem. Moreover, the new procedure (TSA-MISH) allowed to detect differences in AtGUS1 and AtGUS2 expression, not observed by the traditional MISH, evidencing a spatial (cortex versus stele) and temporal (meristem versus transition zone) regulation of AtGUS1 and AtGUS2 expression. In particular from these observations, AtGUS1 appeared to be spatially regulated in the cap being expressed in the columella but not in peripheral layers, and temporally in the epidermis being present in the proximal meristem and disappearing in the elongation zone. Moreover both AtGUS1 and AtGUS2 appeared temporally regulated in the stele, being expressed in the elongation zone and silenced in proximal meristem.

In conclusion, the TSA-MISH technique expands upon the previously one established in Bruno $L$ et al., (2011) and provides the following advantages: a) brilliant hybridization signal with reduced background; b) amplification of signal with low-abundance genes expression which could be underestimated or missed by using MISH; c) reliable concomitant detection of genes with very different levels of expression; namely, in the last case, it could be hard to establish hybridization conditions adapted to avoid either over- or under-estimation of "highy expressed" and "lowly expressed" genes, respectively. Similar difficulty could occur facing single gene expressed at different level in the different organs and tissues. All these aspects are highly relevant when information on the cyto-histological domains of transcript accumulation needs to be acquired.

Finally, a very relevant extension of TSA-MISH technique is the concomitant detection of transcription (mRNA) and translation (proteins) products, in order to analyse the whole regulation of gene expression. In fact, as above mentioned, antibodies versus the encoded protein together with the antibody $v s$ the relative mRNA-probe can be simultaneously detected. Moreover, a combined TSA-MISH and GFP detection has been set up which can be applied for a concomitant detection of mRNA and its encoded protein in GFP-lines transformed for the protein of interest, to overcome the un-availability of protein specific antibody.

\section{Materials and Methods}

\section{Plant material fixation and dehydration}

Seeds of Arabidopsis Thaliana (L.) Heynh. ecotype Columbia (Col) were surface sterilized by incubation in absolute ethanol for $2 \mathrm{~min}$ and $1.75 \%$ hypochlorite solution ( $\mathrm{NaClO}$ ) for $12 \mathrm{~min}$. After thorough washing with sterile distilled water ( $3 \times 5 \mathrm{~min}$ ), the seeds were sown on Petri dishes containing germination medium (GS), $1 \%$ sucrose (Valvekens et al., 1988) and $0.7 \%$ plant cell culture agar (Sigma-Aldrich). The plated seeds were left at $4^{\circ} \mathrm{C}$ for $48 \mathrm{~h}$ to ensure uniform germination, and then moved to a growth chamber at $21^{\circ} \mathrm{C}$, under $16 \mathrm{~h}$ light $\left(150 \mu \mathrm{mol} \mathrm{m}^{-2} \mathrm{~s}^{-1}\right)$ and $8 \mathrm{~h}$ dark and $60 \%$ relative humidity. Five to eight day-old seedlings were fixed in $4 \%(\mathrm{w} / \mathrm{v})$ paraformaldehyde, $15 \%(\mathrm{v} / \mathrm{v})$ DMSO and $0.1 \%$ Tween -20 in PBS $10 \%(\mathrm{w} / \mathrm{v}), 1 \mathrm{M}$ $\mathrm{NaOH}, 1$ XPBS (10XPBS: $1,3 \mathrm{M} \mathrm{NaCl}, 70 \mathrm{mM} \mathrm{Na}{ }_{2} \mathrm{HPO}_{4}, 30 \mathrm{mM} \mathrm{KH}_{2} \mathrm{PO}_{4}$ $\mathrm{pH} 7$ ) and chlorophyll was removed as previously reported (Bruno et al., 2011). Fixed material was stored in absolute ethanol overnight at $-20^{\circ} \mathrm{C}$.

\section{Synthesizing labeled RNA probe}

The following primer sequences AtGUS1 (AT5G61250) FW 5'-TTTGGTCGGAGGTTTCTACG-3'and BW 5'-TTCAAATATCCGTCCGAAGC-3'; AtGUS2 (AT5G07830) FW 5'-GCTACGGGTTTACGCACATT-3' and BW 5'-CAACACACCGTTTTCTGGTG-3; ELO3(At5g50320) FW 5'-TGAAGATACACGCCAGGACA-3' and BW 5'-CACCAGAAATCACACCGATT-3', were used in a PCR reaction to amplify gene-specific fragments (GSTs) 342 , 250 and 300 bp long, respectively (Fig. 1).

Sense and antisense strands were synthesized for each gene by T7 and SP6 RNA polymerase promoter included in the appropriate primer.

Labeled RNA probes were synthesized using in vitro transcription in the presence of Digoxigenin-11-UTP (AtGUS2probe), Biotin-16-UTP (AtGUS1, ELO3 probe) and processed as previously published (Bruno et al., 2011).

\section{In situ hybridization by MISH}

Fixed whole seedlings were permeabilized in a 1:1 mixture of ethanol 
and xylene for $30 \mathrm{~min}$, washed twice in ethanol for $5 \mathrm{~min}$ and progressively rehydrated in $75 \%$ ethanol ( $\mathrm{v} / \mathrm{v}$ in water), $50 \%$ and $25 \%$ ethanol ( $/ / \mathrm{v}$ in $1 \mathrm{X}$ PBS) for $10 \mathrm{~min}$ each. Samples were refixed in fixative solution, for 20 min at room temperature (RT), washed twice in PBT (1X PBS plus $0.1 \%$ $(\mathrm{v} / \mathrm{v})$ Tween-20) for $10 \mathrm{~min}$ and then incubated with $20 \mathrm{\mu g} \mathrm{ml}^{-1}$ proteinase $\mathrm{K}$ (Roche) for $15 \mathrm{~min}$. Digestion was stopped by incubating the samples in $1 \mathrm{X}$ PBS plus $2 \mathrm{mg} \mathrm{ml}^{-1}$ glycine for $5 \mathrm{~min}$ and then washing them twice in PBT for $10 \mathrm{~min}$. Samples were refixed in fixative solution for $10 \mathrm{~min}$ at $\mathrm{RT}$, washed twice in PBT for 10 min and once in the hybridization solution consisting in $50 \%(\mathrm{v} / \mathrm{v})$ formamide in $5 \mathrm{XSSC}$ (20X SSC: $3 \mathrm{M} \mathrm{NaCl}, 300 \mathrm{mM}$ sodium citrate, $\mathrm{pH} 7.0$ with $1 \mathrm{M} \mathrm{HCl}), 0.1 \%(\mathrm{v} / \mathrm{v})$ Tween-20 and $0.1 \mathrm{mg} \mathrm{ml}^{-1}$ of heparin (Sigma) for $10 \mathrm{~min}$, and then preincubated in the same solution for $1 \mathrm{~h}$ at $50^{\circ} \mathrm{C}$. The hybridization step was performed overnight at $50^{\circ} \mathrm{C}$ by incubating samples in hybridization solution, supplemented with $10 \mathrm{ug} \mathrm{ml}^{-1}$ of Salmon sperm DNA, containing denatured $\left(80^{\circ} \mathrm{C}\right.$ for $\left.2 \mathrm{~min}\right)$ AtGUS1 and AtGUS2 labeled RNA probes at $20-100 \mathrm{ng} \mathrm{ml}^{-1}$ final concentration. After hybridization the samples were subjected to the following washing: three times (10 $\mathrm{min}, 60 \mathrm{~min}$ and $20 \mathrm{~min}$ ) in a solution of $50 \%(\mathrm{v} / \mathrm{v})$ formamide, $2 \mathrm{X}$ SSC and $0.1 \%(\mathrm{v} / \mathrm{v})$ Tween- 20 at $50^{\circ} \mathrm{C}$; twice for $20 \mathrm{~min}$ in $2 x \mathrm{SSC}, 0.1 \%$ (v/v) Tween-20 at $50^{\circ} \mathrm{C}$; once for $20 \mathrm{~min}$ in $0.2 x$ SSC, $0.1 \%$ (v/v) Tween-20 at $50^{\circ} \mathrm{C}$; three times for $10 \mathrm{~min}$ in PBT at RT; once for 30 min in PBT plus $1 \%$ BSA (Roche) (PBT+BSA). Thereafter samples were incubated for 2 $\mathrm{h}$ at RT under gentle shaking with a mixture of primary antibodies (sheep anti-digoxigenin, Roche; mouse anti-biotin, INVITROGEN) diluted 1:100 in PBT+BSA. After washing (10 min $\times 3$ in PBT and $30 \mathrm{~min} \times 1$ in PBT+BSA) samples were incubated overnight at $\mathrm{RT}$ in the dark with a mixture of the secondary antibodies (Alexa Fluor dyes 555 Donkey Anti-Sheep, INVITROGEN; Alexa Fluor dyes 488 Donkey Anti-Mouse, INVITROGEN) diluted $1: 100$ in PBT plus BSA. After washing twice for 15 min in PBT under gentle shaking in the dark the samples were whole mounted with antifade reagent (Fluka) on a microscope slide for viewing.

\section{In situ hybridization by TSA-MISH}

Standard prehybridization and multiprobe hybridization were performed as above described. Following hybridization, samples were washed three times (10 min, $60 \mathrm{~min}$ and $20 \mathrm{~min}$ ) in a solution of $50 \%(\mathrm{v} / \mathrm{v})$ formamide, 2X SSC and $0.1 \%(\mathrm{v} / \mathrm{v})$ Tween- 20 at $50^{\circ} \mathrm{C}$, twice for $20 \mathrm{~min}$ in $2 \mathrm{x} \mathrm{SSC}$, $0.1 \%(\mathrm{v} / \mathrm{v})$ Tween- 20 at $50^{\circ} \mathrm{C}$ and once for $20 \mathrm{~min}$ in $0.2 \mathrm{XSSC}, 0.1 \%(\mathrm{v} / \mathrm{v})$ Tween-20 at $50^{\circ} \mathrm{C}$. Sample were then washed three times in PBT for 10 min. and incubated for $60 \mathrm{~min}$. at RT in $0.2 \mathrm{X} \mathrm{SSC}$ with $1 \%(\mathrm{v} / \mathrm{v}) \mathrm{H}_{2} \mathrm{O}_{2}$ to inactivate endogenous peroxidase activity and washed twice for $30 \mathrm{~min}$ in PBT at RT. Thereafter samples were preincubated in PBT+BSA for 30 min at $\mathrm{RT}$ and incubated overnight at $4^{\circ} \mathrm{C}$ under gentle shaking in PBT+BSA in the presence of mouse anti-biotin and rabbit anti-digoxigenin monoclonal antibodies (INVITROGEN) diluted 1:500 (AtGUS1 and AtGUS2 detection, respectively). After washing four times for $20 \mathrm{~min}$ in PBT and once for 30 min in PBT plus $1 \%$ BSA (Roche) at RT, the samples were incubated with HRP-goat anti-mouse IgG for 60 min at RT without shaking. After washing for 30 min in PBS $1 X$ at RT, the samples were incubated for 60 min at RT in the presence of Alexa 488-conjugated tyramide, in the INVITROGEN amplification reagent working solution. This step allowed to detect the presence of biotin, i.e. of GUS1 transripts. After washing at RT in darkness (30 min X 2 in PBT) samples were incubated for 60 min at RT in $4 \% \mathrm{v} / \mathrm{v}_{2} \mathrm{O}_{2}$ to inactivate the peroxidase conjugated to the anti-mouse HRP-antibody.

Following $\mathrm{H}_{2} \mathrm{O}_{2}$ treatment, the above reported procedure has been repeated using HRP-goat anti-rabbit IgG (anti-dig) (INVITROGEN) diluted 1:100 (AtGUS2 detection). After washing for $30 \mathrm{~min}$ in PBS $1 \mathrm{X}$ at RT, the samples were incubated for $60 \mathrm{~min}$ at RT in the presence of Alexa 555 -conjugated tyramide in the amplification reagent working solution, as described in INVITROGEN protocol. This step allowed to detect the presence of digoxigenin, i.e. of AtGUS2 transripts.

Samples were then washed twice for $30 \mathrm{~min}$ in PBT at RT and whole mounted with antifade reagent (Fluka) on a microscope slide for viewing.

The same procedure above reported for AtGUS1 has been performed for $E L O 3$ single probe.

\section{Combined GFP detection and TSA-MISH}

The above described TSA-MISH procedure for AtGUS1 detection has been used. Rabbit anti - denatured GFP antibody (gentle gift from professor Takeshi Kaneko), at a final concentration of $100 \mathrm{ng} / \mathrm{ml}$, was concomitantly added with the HRP-goat anti mouse. At the end of the TSA-MISH procedure for AtGUS1 detection, i.e. following the $4 \% \mathrm{v} / \mathrm{v} \mathrm{H}_{2} \mathrm{O}_{2}$ tretament, samples were washed three times for $10 \mathrm{~min}$ in PBT at RT and once for $30 \mathrm{~min}$ in PBT plus 1\% BSA (Roche) (PBT+BSA). Thereafter they were incubated for $2 \mathrm{~h}$ at $\mathrm{RT}$ under gentle shaking with Donkey Anti-rabbit conjugated to Alexa Fluor dye 647 (INVITROGEN), diluted 1:500. After washing twice for 15 min in PBT under gentle shaking in the dark, the samples were whole mounted with antifade reagent (Fluka) on a microscope slide for viewing.

\section{Confocal visualization}

Samples were imaged using a Leica inverted TCS SP8 confocal scanning laser microscope. Simultaneous detection of Alexa Fluor dyes was performed by combining the settings indicated in the sequential scanning facility of the microscope.

\section{Acknowledgements}

We thank Prof. Takeshi Kaneko, Department of Morphological Brain Science, Graduate School of Medicine, Kyoto University, for providing antibodies against heat denatured GFP used in this study. This work was supported by grants from the University of Calabria -Italy (ex 60\%). The instruments for this research were supplied by PON Ricerca e Competitività 2007-2013, Sistema Integrato di Laboratori per L'Ambiente - (SILA) PONa3_00341 Piattaforma Tecnologica di Omica Integrata: Genomica Proteomica Metabolomica.

\section{References}

AlWen, A., MORENO, R., ViCENTE, O. and HEBERLE-BORS, E. (1992). Plant endogenous $\beta$-glucuronidase activity: how to avoid interference with the use of the $E$. coli $\beta$-glucuronidase as a reporter gene in transgenic plants. Transgenic Res 1: 63-70.

ANHALT, S. and WEISSENBÖCK, G. (1992). Subcellular localization of luteolin glucuronides and related enzymes in rye mesophyll. Planta 187: 83-88-88.

ARUL, L., BENITA, G., SUDHAKAR, D., THAYUMANAVAN, B. and BALASUBRAMANIAN, P. (2008). Beta-glucuronidase of family-2 glycosyl hydrolase: a missing member in plants. Bioinformation 3: 194-197.

BLILOU, I., XU, J., WILDWATER, M., WILLEMSEN, V., PAPONOV, I., FRIML, J., HEIDSTRA, R., AIDA, M., PALME, K. and SCHERES, B. (2005). The PIN auxin efflux facilitator network controls growth and patterning in Arabidopsis roots. Nature 433: 39-44.

BOKMAN, S.H. and WARD, W.W. (1981). Renaturation of Aequorea green-fluorescent protein. Biochem Biophys Res Comm 101: 1372-1380.

BRUNO, L., MUTO, A., SPADAFORA, N., IARIA, D., CHIAPPETTA, A., VAN LIJSEBETTENS, M. and BITONTI, M. (2011). Multi-probe in situ hybridization to whole mount Arabidopsis seedlings Int J Dev Biol 55: 197-203.

CLOWES, F.A.L. (1954). The promeristem and the minimal constructional centre in grass root apices. New Phytol 53: 108-116.

DARBY, I.A., BISUCCI, T., DESMOULIĖRE, A. and HEWITSON, T.D. (2006). In In situ Hybridization Protocols, vol. 326 (ed. DARBY, I. A. and HEWITSON, T. D.). Humana Press, pp.17-31.

DELLO IOIO, R., LINHARES, F.S., SCACCHI, E., CASAMITJANA-MARTINEZ, E., HEIDSTRA, R., COSTANTINO, P. and SABATINI, S. (2007). Cytokinins Determine Arabidopsis Root-Meristem Size by Controlling Cell Differentiation. Curr Biol 17: 678-682.

DOLAN, L., JANMAAT, K., WILLEMSEN, V., LINSTEAD, P., POETHIG, S., ROBERTS, K. and SCHERES, B. (1993). Cellular organisation of the Arabidopsis Thaliana root. Development 119: 71-84.

EUDES, A., MOUILLE, G., THÉVENIN, J., GOYALLON, A., MINIC, Z. and JOUANIN, L. (2008). Purification, Cloning and Functional Characterization of an Endogenous beta-Glucuronidase in Arabidopsis Thaliana. Plant Cell Physiol 49: 1331-1341. 
HAFIDH, S., BREZNENOVA, K., RUZICKA, P., FECIKOVA, J., CAPKOVA, V. and HONYS, D. (2012). Comprehensive analysis of tobacco pollen transcriptome unveils common pathways in polar cell expansion and underlying heterochronic shift during spermatogenesis. BMC Plant Biol 12: 24.

HENRISSAT, B. (1991). A classification of glycosyl hydrolases based on amino acid sequence similarities. Biochem. J. 280: 309-316.

HENRISSAT, B. and BAIROCH, A. (1993). New families in the classification of glycosyl hydrolases based on amino acid sequence similarities. Biochem. J. 293: 781-788.

HENRISSAT, B. and BAIROCH, A. (1996). Updating the sequence-based classification of glycosyl hydrolases. Biochem. J. 316: 695-696.

HIMANEN, K., WOLOSZYNSKA, M., BOCCARDI, T.M., DE GROEVE, S., NELISSEN, H., BRUNO, L., VUYLSTEKE, M., VAN LIJSEBETTENS, M. (2012). Histone H2B monoubiquitination is required to reach maximal transcripts levels of circadian clock genes in Arabidopsis. Plant J. 72: 249-260.

HIRUNUMA, M., SHOYAMA, Y., SASAKI, K., SAKAMOTO, S., TAURA, F., SHOYAMA, Y., TANAKA, H. and MORIMOTO, S. (2011). Flavone-catalyzed apoptosis in Scutellaria baicalensis. Phytochemistry 72: 752-760.

HONYS, D. and TWELL, D. (2004). Transcriptome analysis of haploid male gametophyte development in Arabidopsis. Genome Biol 5: R85.

HU, C.-Y., CHEE, P.P., CHESNEY, R.H., ZHOU, J.H., MILLER, P.D. and O'BRIEN, W.T. (1990). Intrinsic GUS-like activities in seed plants. Plant Cell Rep 9: 1-5.

ISHII, T. and MATSUNAGA, T. (1996). Isolation and characterization of a boronrhamnogalacturonan-II complex from cell walls of sugar beet pulp. Carbohydr Res 284: 1-9.

KONISHI, T., KOTAKE, T., SORAYA, D., MATSUOKA, K., KOYAMA, T., KANEKO, S., IGARASHI, K., SAMEJIMA, M. and TSUMURAYA, Y. (2008). Properties of family 79 [beta]-glucuronidases that hydrolyze [beta]-glucuronosyl and 4-O-methyl-[beta]glucuronosyl residues of arabinogalactan-protein. Carbohydr Res343: 1191-1201.

KOUTANIEMI, S., GUILLON, F., TRANQUET, O., BOUCHET, B., TUOMAINEN, P., VIRKKI, L., PETERSEN, H., WILLATS, W.T., SAULNIER, L. and TENKANEN, M. (2012). Substituent-specific antibody against glucuronoxylan reveals close association of glucuronic acid and acetyl substituents and distinct labeling patterns in tree species. Planta 236: 739-751.

LEE, M.-H., KIM, B., SONG, S.-K., HEO, J.-O., YU, N.-I., LEE, S., KIM, M., KIM, D., SOHN, S., LIM, C. et al., (2008). Large-scale analysis of the GRAS gene family in Arabidopsis Thaliana. Plant Mol Biol 67: 659-670.

MATAS, A.J., YEATS, T.H., BUDA, G.J., ZHENG, Y., CHATTERJEE, S., TOHGE, T., PONNALA, L., ADATO, A., AHARONI, A., STARK, R. et al., (2011). Tissue- and Cell-Type Specific Transcriptome Profiling of Expanding Tomato Fruit Provides Insights into Metabolic and Regulatory Specialization and Cuticle Formation. Plant Cell 23: 3893-3910.

MORIMOTO, S., HARIOKA, T. and SHOYAMA, Y. (1995). Purification and characterization of flavone-specific beta-glucuronidase from callus-cultures of Scutellaria baicalensis Georgi. Planta 195: 535-540.

MORIMOTO, S., TATEISHI, N., MATSUDA, T., TANAKA, H., TAURA, F., FURUYA, N., MATSUYAMA, N. and SHOYAMA, Y. (1998). Novel hydrogen peroxide metabolism in suspension cells of Scutellaria baicalensis Georgi. JBiol Chem273: 12606-12611.

MOUBAYIDIN, L., DI MAMBRO, R., SOZZANI, R., PACIFICI, E., SALVI, E., TERPSTRA, I., BAO, D., VAN DIJKEN, A., DELLO IOIO, R., PERILLI, S. et al., (2013). Spatial Coordination between Stem Cell Activity and Cell Differentiation in the Root Meristem. Dev Cell 26: 405-415.

MUHITCH, M.J. (1998). Characterization of pedicel beta-glucuronidase activity in developing maize (Zea mays) kernels. Physiol Plant 104: 423-430.

NAKAMURA, K.C., KAMEDA, H., KOSHIMIZU, Y., YANAGAWA, Y. and KANEKO, T. (2008). Production and Histological Application of Affinity-purified Antibodies to Heat-denatured Green Fluorescent Protein. J Histochem Cytochem 56: 647-657.

NELISSEN, H., DE GROEVE, S., FLEURY, D., NEYT, P., BRUNO, L., BITONTI, M.B., VANDENBUSSCHE, F., VAN DER STRAETEN, D., YAMAGUCHI, T., TSUKAYA, H., WITTERS, E., DE JAEGER, G., HOUBEN, A. and VAN LIJSEBETTENS, M. (2010). Plant Elongator regulates auxin-related genes during RNA polymerase II transcription elongation. Proc. Natl. Acad. Sci. USA 107: 1678-1683.
PINA, C., PINTO, F., FEIJÓ, J.A. and BECKER, J.D. (2005). Gene Family Analysis of the Arabidopsis Pollen Transcriptome Reveals Biological Implications for Cell Growth, Division Control, and Gene Expression Regulation. Plant Physiol 138: 744-756.

PLEGT, L. and BINO, R.J. (1989). $\beta$-Glucuronidase activity during development of the male gametophyte from transgenic and non-transgenic plants. Mol Gen Genet 216: 321-327.

PYSH, L.D., WYSOCKA-DILLER, J.W., CAMILLERI, C., BOUCHEZ, D. and BENFEY, P.N. (1999). The GRAS gene family in Arabidopsis: sequence characterization and basic expression analysis of the SCARECROW-LIKE genes. Plant J 18: 111-119.

RENARD, C.M.G.C., CRÉPEAU, M.-J. and THIBAULT, J.-F. (1999). Glucuronic acid directly linked to galacturonic acid in the rhamnogalacturonan backbone of beet pectins. Eur J Biochem 266: 566-574.

SASAKI, K., TAURA, F., SHOYAMA, Y. and MORIMOTO, S. (2000). Molecular Characterization of a Novel $\beta$-Glucuronidase from Scutellaria baicalensis Georgi. $J$ Biol Chem 275: 27466-27472.

SCHERES, B. (2007). Stem-cell niches: nursery rhymes across kingdoms. Nat Rev Mol Cell Biol 8: 345-354.

SCHOENBECK, M.A., SWANSON, G.A. and BROMMER, S.J. (2007). Beta-glucuronidase activity in seedlings of the parasitic angiosperm Cusctua pentagona: developmental impact of the beta-glucuronidase inhibitor saccharic acid 1,4-lactone. Funct Plant Biol 34: 811-821.

SCHULZ, M. and WEISSENBÖCK, G. (1987). Partial purification and characterization of a luteolin triglucuronide-specific beta-glucuronidase from rye primary leaves (Secale cereale). Phytochemistry 26: 933-937.

SOOD, P. (1980). Histoenzymological compartmentation of $\beta$-glucuronidase in the germinating pollen grains of Portulaca grandiflora. Biol Plantarum 22: 124-127.

SUDAN, C., PRAKASH, S., BHOMKAR, P., JAIN, S. and BHALLA-SARIN, N. (2006). Ubiquitous presence of beta-glucuronidase (GUS) in plants and its regulation in some model plants. Planta 224: 853-864.

URBANOWICZ, B.R., PEÑA, M.J., RATNAPARKHE, S., AVCI, U., BACKE, J., STEET, H.F., FOSTON, M., LI, H., O'NEILL, M.A., RAGAUSKAS, A.J. et al., (2012). 4-O-methylation of glucuronic acid in Arabidopsis glucuronoxylan is catalyzed by a domain of unknown function family 579 protein. Proc Natl Acad Sci USA 109: 14253-14258

VALVEKENS, D., MONTAGU, M.V. and LIJSEBETTENS, M.V. (1988). Agrobacterium tumefaciens-mediated transformation of Arabidopsis Thaliana root explants by using kanamycin selection. Proc Natl Acad Sci USA 85: 5536-5540.

WARD, W.W. (1981). Properties of the coelenterate green fluorescent protein In Bioluminescence and Chemioluminescence, (ed. DELUCA, M. and MCELROY, W. D.). Academic Press, New York, pp.235-242.

WARD, W.W. and BOKMAN, S.H. (1982). Reversible denaturation of Aequorea greenfluorescent protein: physical separation and characterization of the renatured protein. Biochemistry 21: 4535-4540.

WEN, F., WOO, H.-H., HIRSCH, A. and HAWES, M. (2004). Lethality of inducible, meristem-localized ectopic $\beta$-glucuronidase expression in plants. Plant Mol Biol Rep 22: 7-14.

WOO, H.-H., JEONG, B. and HAWES, M. (2005). Flavonoids: from cell cycle regulation to biotechnology. Biotechnol Lett 27: 365-374-374.

WOO, H.-H., JEONG, B.R., HIRSCH, A.M. and HAWES, M.C. (2007). Characterization of Arabidopsis AtUGT85A and AtGUS gene families and their expression in rapidly dividing tissues. Genomics 90: 143-153.

WOZNIAK, C.A. and OWENS, L.D. (1994). Native beta-glucuronidase activity in sugar-beet (Beta vulgaris). Physiol Plant 90: 763-771.

ZHONG, R., PEÑA, M.J., ZHOU, G.-K., NAIRN, C.J., WOOD-JONES, A., RICHARDSON, E.A., MORRISON, W.H., DARVILL, A.G., YORK, W.S. and YE, Z.-H. (2005). Arabidopsis Fragile Fiber8, Which Encodes a Putative Glucuronyltransferase, Is Essential for Normal Secondary Wall Synthesis. Plant Cell 17: 3390-3408. 


\section{Further Related Reading, published previously in the Int. J. Dev. Biol.}

Role of plant expression systems in antibody production for passive immunization

Vikram Virdi and Ann Depicker

Int. J. Dev. Biol. (2013) 57: 587-593

http://dx.doi.org/10.1387/ijdb.130266ad

Genetic transformation of major cereal crops

Qing Ji, Xing Xu and Kan Wang

Int. J. Dev. Biol. (2013) 57: 495-508

http://dx.doi.org/10.1387/ijdb.130244kw

Higher plant transformation: principles and molecular tools

Sylvester Anami, Elizabeth Njuguna, Griet Coussens, Stijn Aesaert and Mieke Van Lijsebettens Int. J. Dev. Biol. (2013) 57: 483-494

http://dx.doi.org/10.1387/ijdb.130232mv

Relationship between brassinosteroids and genes controlling stomatal production in the Arabidopsis hypocotyl

Sonia Fuentes, Roberto C. Cañamero and Laura Serna

Int. J. Dev. Biol. (2012) 56: 675-680

http://dx.doi.org/10.1387/ijdb.120029ls

Reproductive Meristem22 is a unique marker for the early stages of stamen development Elisson Romanel, Pradeep Das, Richard M. Amasino, Jan Traas, Elliot Meyerowitz and Marcio Alves-Ferreira

Int. J. Dev. Biol. (2011) 55: 657-664

http://dx.doi.org/10.1387/ijdb.113340er

Multi-probe in situ hybridization to whole mount Arabidopsis seedlings

Leonardo Bruno, Antonella Muto, Natasha D. Spadafora, Domenico laria, Adriana Chiappetta, Mieke Van Lijsebettens and Maria B. Bitonti

Int. J. Dev. Biol. (2011) 55: 197-203

http://dx.doi.org/10.1387/ijdb.103132lb

Female gametophytic mutants of Arabidopsis Thaliana identified in a gene trap insertional mutagenesis screen

Vladimir B. Brukhin, Miloslawa Jaciubek, Arturo Bolaños Carpio, Vera Kuzmina and Ueli Grossniklaus

Int. J. Dev. Biol. (2011) 55: 73-84

http://dx.doi.org/10.1387/ijdb.092989vb

5 yr ISI Impact Factor $(2013)=2.879$
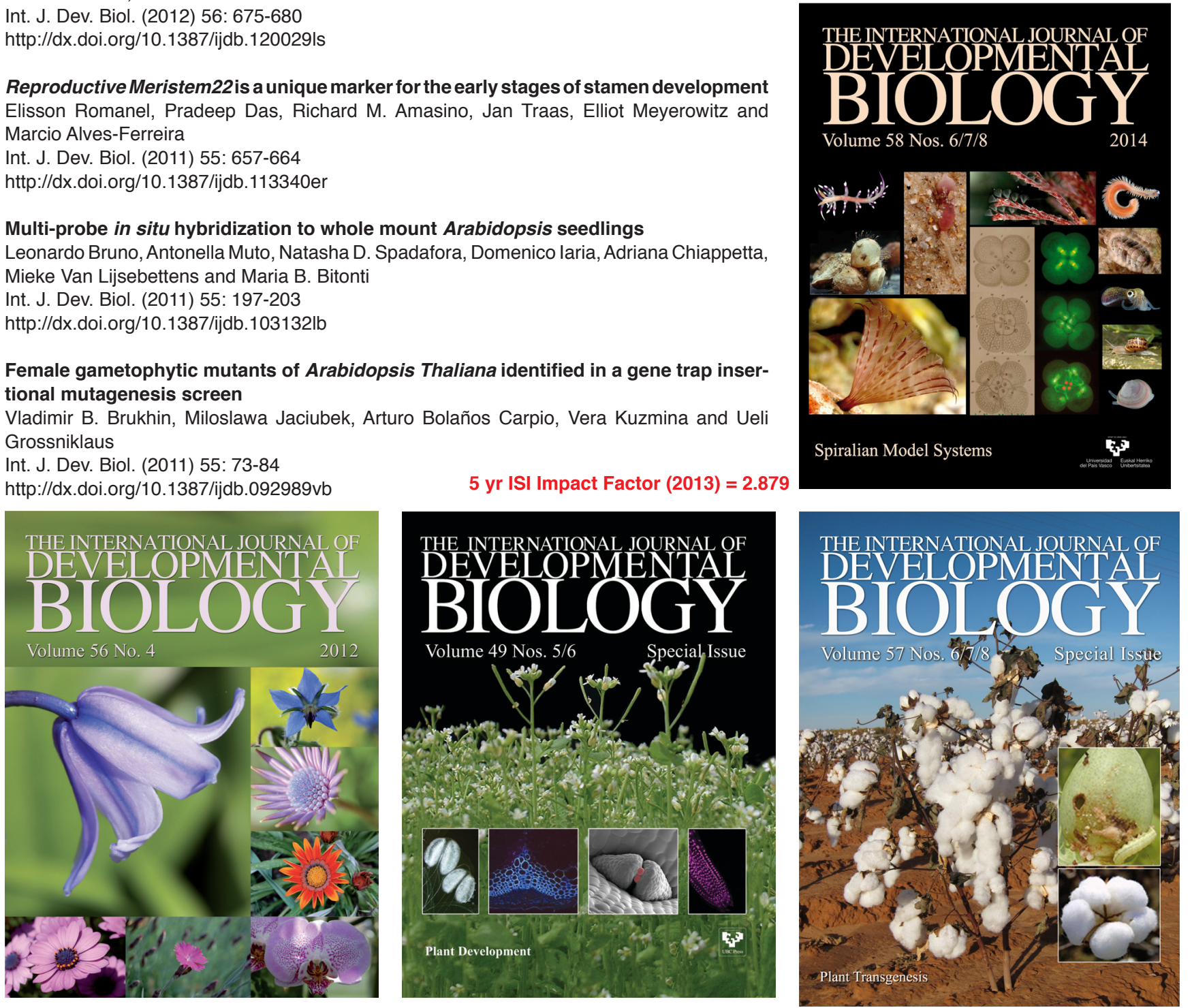